\title{
First report of Pythium root rot of chrysanthemum in Vietnam and control with metalaxyl drench
}

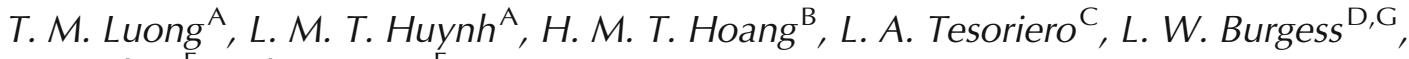 \\ H. T. Phan ${ }^{\mathrm{E}}$ and P. Davies ${ }^{\mathrm{F}}$ \\ ${ }^{A}$ Quang Nam Plant Protection Sub-Department, Tam Ky, Quang Nam, Vietnam. \\ BTTHUE Plant Protection Sub-Department, Hue, Vietnam. \\ CElizabeth Macarthur Agricultural Institute, PMB 8, Camden, NSW 2570, Australia. \\ DFaculty of Agriculture, Food and Natural Resources, The University of Sydney, NSW 2006, Australia. \\ ${ }^{E}$ National Institute of Medicinal Materials, 3B Quang Trung St., Hanoi, Vietnam. \\ FPlant Breeding Institute, Faculty of Agriculture, Food and Natural Resources, The University of Sydney, \\ Private Bag 2570, Camden, NSW 2570, Australia. \\ ${ }^{\mathrm{G} C o r r e s p o n d i n g ~ a u t h o r . ~ E m a i l: ~ b u r g e s s . i n t e r n a t i o n a l @ g m a i l . c o m ~}$
}

\begin{abstract}
This is the first report of Pythium root rot of chrysanthemum, and the pathogen responsible, Pythium aphanidermatum, from Quang Nam and TT Hue Provinces in Vietnam. The typical symptoms included stunting, wilting, and necrosis of the main, lateral and feeder rootlets. A black necrotic lesion girdling the lower stem was present in some diseased plants. The root rot commonly caused death of diseased plants and affected plants at all growth stages. The pathogen was also isolated from transplants affected by root rot, and sampled directly from boxes transported from Dalat, Lam Dong Province, the source of most transplants used in Quang Nam. Metalaxyl was shown to provide effective control of Pythium root rot in a field trial when used to dip transplants before planting, and as a regular drench. Metalaxyl also provided effective control of the disease in commercial crops on the farm where the field was located.
\end{abstract}

A chrysanthemum farmer, Mr Quoi Nguyen, noted that some chrysanthemum plants wilted and died in 2005, on his farm in Cam Ha Commune, Hoi An Town, Quang Nam Province, Vietnam. In May 2007 he reported a high incidence of wilted, stunted and dead plants, and the authors visited the farm. Plants were affected by the disease at all growth stages, from young transplants (Fig. 1) through to the flowering stage (Figs 2-4). Diseased plants were stunted with poor root development and obvious rot of the tap root and lateral roots (Figs 2-4). A black necrotic lesion extended upward for $10-20 \mathrm{~cm}$ from the base of the stem on several diseased plants (Fig. 4). In addition, the development of small feeder rootlets was restricted and the few rootlets present were necrotic. We did not observe vascular discolouration or bacterial ooze in any of the plants examined. The symptoms were indicative of Pythium root rot of chrysanthemums (Lumsden and Haasis 1964). The farm was on a sandy soil in old sand-dune land that had been levelled, within $10 \mathrm{~km}$ of the coast. The soil is similar to that where Phoma terrestris was first reported in onions in the Thang Binh District, Quang Nam Province, in Vietnam (Luong et al. 2008).

Samples of diseased plants and 10 composite samples of rootzone soil were collected for laboratory diagnosis and accessioned as BTQ 84 in the records of the diagnostic laboratory at the Quang Nam Plant Protection Sub-Department (PPSD). The roots were washed thoroughly in tap water, surface-sterilised by dipping

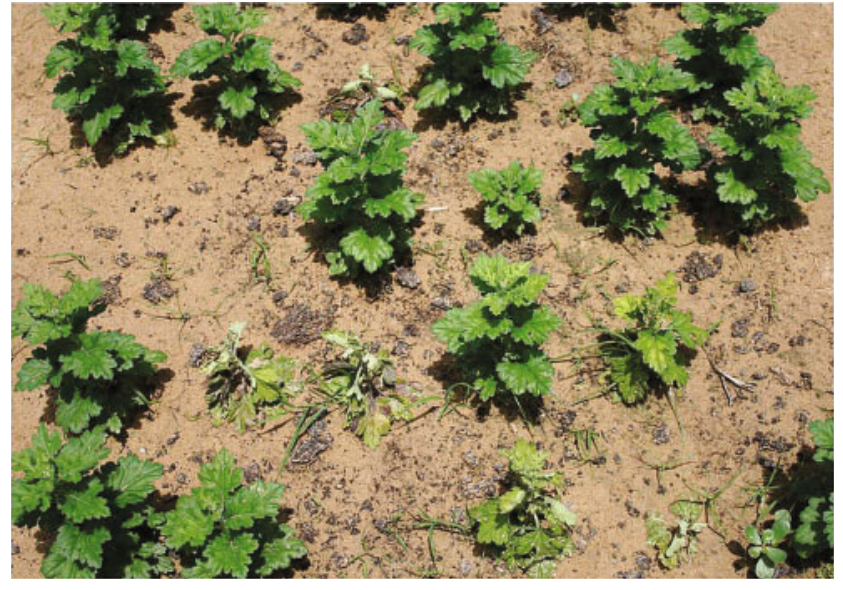

Fig. 1. Young dead and wilting chrysanthemum plants, in situ, affected by Pythium root rot caused by Pythium aphanidermatum.

briefly in 70\% ethyl alcohol, immediately rinsed in sterile water and damp-dried on sterile paper tissue. Root segments, 3-5 mm long, from the margin of symptomless and necrotic tissue were plated in water agar (WA) as described in Burgess et al. (2008). The composite soil samples were well mixed, sub-samples were 


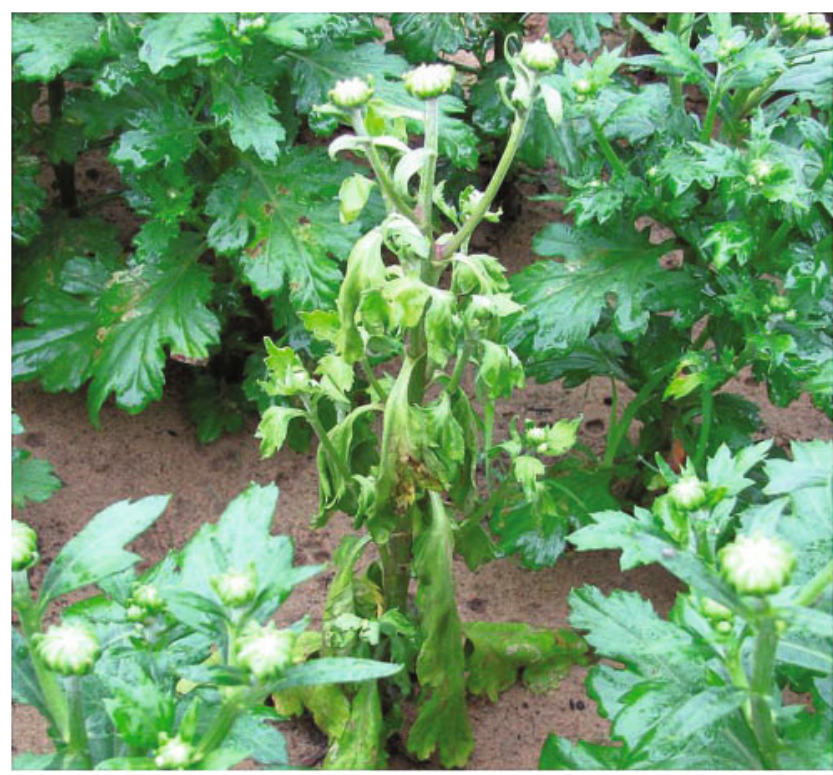

Fig. 2. Wilted chrysanthemum plant, in situ, affected by Pythium root rot caused by Pythium aphanidermatum.

removed and added to sterile water in small plastic cups and then baited with rose petals, as described in Burgess et al. (2008), to isolate Pythium species, if present. A Pythium species was consistently isolated from root segments and baited from the soil samples. Cultures were purified by hyphal tipping (Burgess et al. 2008) and identified morphologically as $P$. aphanidermatum based on the description in Plaats-Niterink (1981). Water agar and potato carrot agar (PCA) cultures, and rice-leaf water cultures (RLW) produced characteristic sessile, intercalary and diclinous antheridia that were almost square in shape. Oospores were distinctly aplerotic. In flooded WA and PCA cultures, and RLW cultures, filamentous inflated sporangia were formed. The sporangia gave rise to numerous vesicles from which abundant zoospores were formed and released. Representative pure cultures were stored in sterile water under the accession numbers QN 73 and QN 74 at the Quang Nam PPSD. The morphological identification was confirmed by the fifth author at the Elizabeth Macarthur Agricultural Institute, Camden, Australia, under accession numbers DAM456 (QN 73) and DAM457 (QN 74). P. aphanidermatum was later isolated from wilted transplants (cuttings) sampled directly from boxes of transplants shipped from Dalat, Lam Dong Province, the main source of chrysanthemum cuttings for the flower industry in Hoi An.

Following the original diagnosis, Pythium root rot of chrysanthemum was observed on other farms in Hoi An, and later observed in TT Hue Province by the third author who also isolated $P$. aphanidermatum from diseased roots.

The farmer was advised to dip transplants in metalaxyl fungicide (Ridomil $^{\circledR} 72$ WP, Syngenta, Switzerland) immediately before planting, and then drench established plants every 2 weeks, pending field trials on efficacy. The metalaxyl treatments proved very effective in the farm-scale trial. The farmer actually sprayed every week, giving concern that the pathogen might develop reduced sensitivity to the

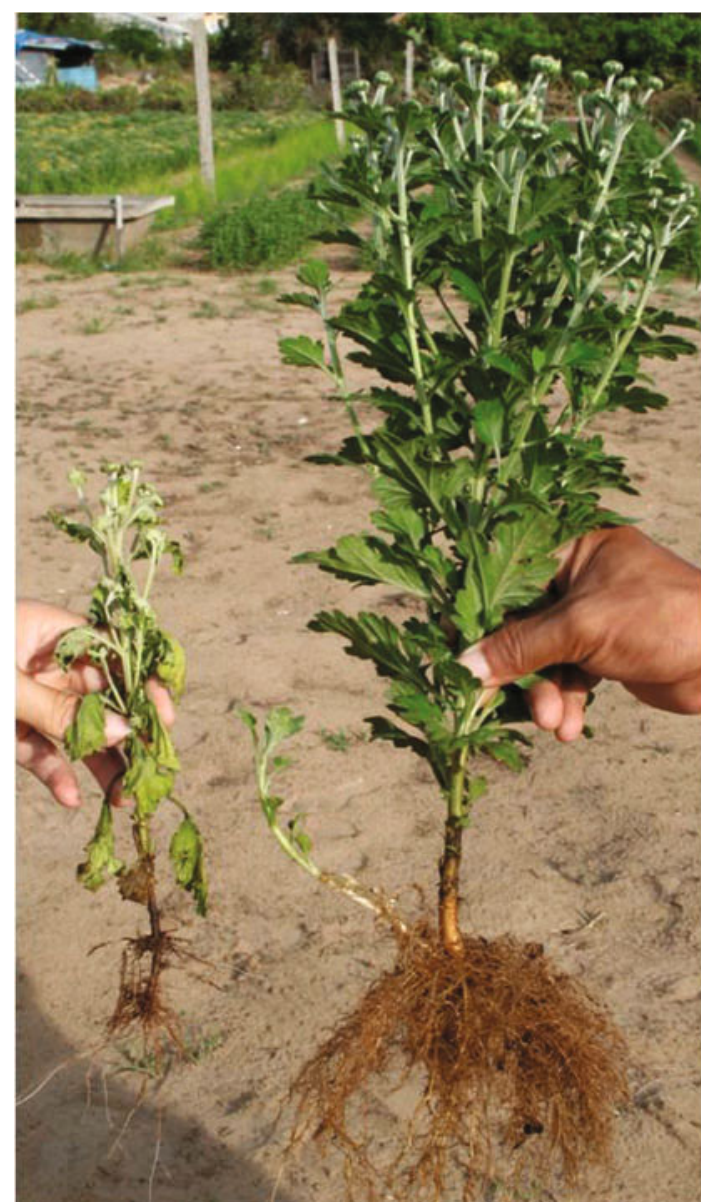

Fig. 3. Stunted and wilted chrysanthemum plant with severe root rot caused by Pythium aphanidermatum (on left), in comparison to symptomless plant.

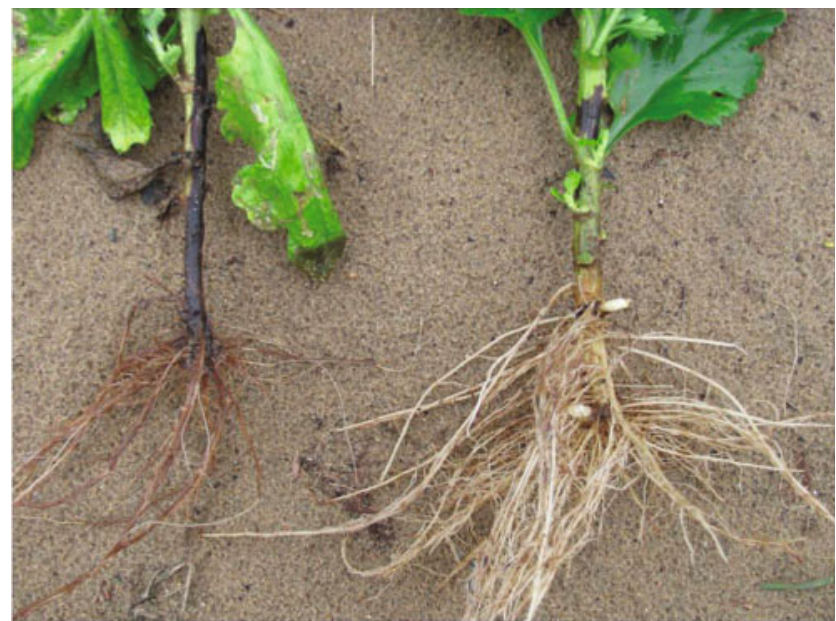

Fig. 4. Stunted and wilted chrysanthemum plant with severe root rot and a girdling black lesion of lower stem, caused by Pythium aphanidermatum (on left), in comparison to symptomless plant. 
fungicide (Sanders 1984) or reduced persistence in soil (Davison and McKay, 2002). Metalaxyl was used in irregular rotation with fosetyl Al(Alliette ${ }^{\circledR} 800 \mathrm{WG}$, Bayer, Germany), as determined by availability, in chrysanthemum crops on this farm, and both remained effective after 2 years. However, the sustained usefulness of metalaxyl is unlikely given the issues of both reduced sensitivity and reduced persistence described in the studies previously cited.

A field trial was established in September 2007 at Mr Quoi's farm to verify the efficacy of metalaxyl by comparison with carbendazim, and water as a control. A randomised complete block design was used. There were five replicate plots per treatment. Each plot was $2 \mathrm{~m} \times 1 \mathrm{~m}$ and was planted with 66 transplants. The transplants were dipped in the relevant fungicide or water immediately before planting. Metalaxyl was used at a rate of $0.5 \mathrm{~g}$ active ingredient (ai) $/ \mathrm{L}$ and the carbendazim at $0.625 \mathrm{gai} / \mathrm{L}$, for dipping and drenching. The plants were drenched at 2, 4 and 6 weeks after planting. Drenching involved the application of $4 \mathrm{~L}$ of fungicide solution or water per plot $\left(2 \mathrm{~m}^{2}\right)$. The number of dead plants in each plot was

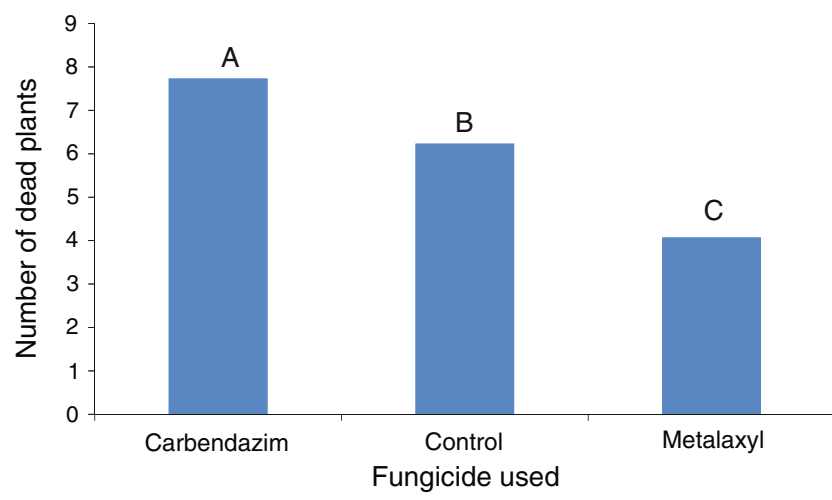

Fig. 5. Relationship between death of chrysanthemum plants at the flowering stage ( 8 weeks) caused by Pythium root rot, and application by drenching of two fungicides, metalaxyl and carbendazim with water as a control. Bars with the same letter are not significantly different.

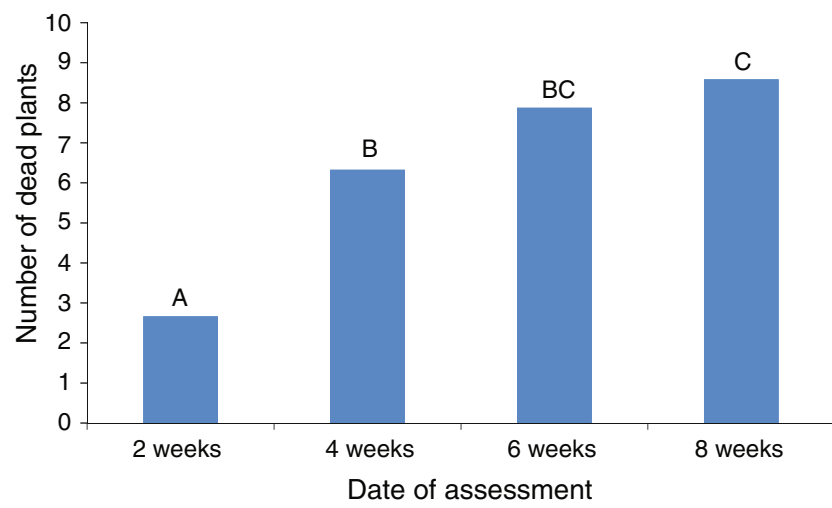

Fig. 6. Relationship between death of chrysanthemum plants caused by Pythium root rot and time after transplanting. Bars represent the average plant death for treatments involving drenching with the fungicides metalaxyl or carbendazim, or with water (control). Bars with the same letter are not significantly different. determined at 2, 4, 6 and 8 weeks after transplanting. A generalised linear mixed model analysis, with Poisson distribution and logarithmic link function was used to analyse the results. The effects of fungicide treatments and the timing of fungicide applications are shown in Figs 5 and 6, respectively.

Metalaxyl significantly reduced plant deaths from $P$. aphanidermatum in the field trial by comparison with the carbendazim and control treatments. It also showed that there was no significant interaction between fungicide and timing of application. That is, the effect of each fungicide did not change, relative to the other fungicides, at different times of application. Carbendazim significantly increased the number of dead plants at all four assessments. It is possible that carbendazim inhibited fungal antagonists that normally inhibit Pythium. Such inhibition could favour infection and more severe root rot. A similar effect was observed on a wet stem rot of cowpeas caused by Pythium aphanidermatum with the use of benomyl and related fungicides (Williams and Ayanaba 1975; Sanders 1984). Carbendazim and several other fungicides are being considered for the control of fungal leaf spots on chrysanthemums in Hoi An. Consequently, further studies are needed on the influence of these fungicides on the severity of Pythium root rot on the sandy soils in this area.

A brochure was produced for farmer training to promote integrated disease management strategies for the disease, namely, raised beds and good drainage, pathogen-free transplants, the dipping of transplants and subsequent drenching with metalaxyl. It is necessary to dip transplants before planting as some shipments were found to be infected with $P$. aphanidermatum. A reliable source of pathogen-free transplants was not available.

This is the first report of the occurrence of Pythium root rot of chrysanthemum in Quang Nam and TT Hue Provinces in Vietnam. It is also the first formal report of Pythium aphanidermatum in Vietnam. It is likely that the disease occurs in other chrysanthemum production areas of Vietnam as the pathogen has been found to cause root rot and seedling death in several other crops in other provinces (T. M. Luong, L. M. T. Huynh, H. M. T. Hoang, L. A. Tesoriero, L. W. Burgess, H. T. Phan and P. Davies, unpubl. data).

Further studies on the distribution and economic importance of $P$. aphanidermatum and other plant pathogenic species of Pythium in Vietnam are justified, given that the high rainfall in most regions is likely to be conducive to this pathogen and some crops are grown annually in the same fields.

\section{Acknowledgements}

The authors gratefully acknowledge financial support from the Australian Centre for International Agricultural Research (ACIAR) through CP/2002/ 115 - Diseases of crops in the central provinces of Vietnam: diagnosis, extension and control (2005-2008).

\section{References}

Burgess LW, Knight T, Tesoriero L, Phan HT (2008) 'Diagnostic manual for plant diseases in Vietnam.' ACIAR Monograph 129. (Australian Centre for International Agricultural Research: Canberra)

Davison EM, McKay AG (2002) Reduced persistence of metalaxyl in soil associated with its failure to control cavity spot of carrots. Plant Pathology 48, 830-835. 
Lumsden RD, Haasis FA (1964) Pythium root and stem diseases of chrysanthemum in North Carolina. North Carolina Agricultural Experiment Station Technical Bulletin 158, 1-27.

Luong TM, Huynh LMT, Tran U, Dau VT, Burgess LW, Phan HT, Aveskamp MM, Vo AD (2008) First report of Phoma terrestris causing pink root rot of Chinese onion in Vietnam. Australasian Plant Disease Notes 3, 147-149.

Plaats-Niterink AJ (1981) 'Monograph of the genus Pythium.' Studies in Mycology No. 21.
Sanders PL (1984) Failure of metalaxyl to control Pythium blight on turfgrass in Pennsylvania. Plant Disease 68, 776-777. doi:10.1094/ PD-69-776

Williams RJ, Ayanaba A (1975) Increased incidence of Pythium stem rot in cowpeas treated with benomyl and related fungicides. Phytopathology 65, 217-218. doi:10.1094/Phyto-65-217

Manuscript received 3 March 2010, accepted 10 May 2010 